\title{
Experimental Investigation on Concealed Multi-ribbed Frame Thermal Insulation Wall under Eccentric Load
}

\author{
Ye-ke Luo \\ Civil Engineering Department, Zhejiang Industry Polytechnic College, Shaoxing 312000,China
}

Keywords: Concealed Multi-ribbed Frame Thermal Insulation Wall, Eccentric load, Experimental Study, Cooperative Work, Failure Mode, Bearing Capability

\begin{abstract}
Four models of Concealed multi-ribbed frame thermal insulation walls are manufactured at $1 / 2$ scale and then tested under eccentric load. The wall's failure processes is described. Cooperative working action, failure modes and bearing capability are analyzed to obtain the bearing capability calculation formula. Research indicates that the phenomenon of the wall's failure is coincide with reinforced concrete structures which under small and large eccentric load. The conclusion shows that the multi-ribbed frame and the blocks can work well together. The result of the calculation formula agrees conservatively with the test results. With high reliability, the formula may be used to calculate the bearing capability of this type of wall.
\end{abstract}

\section{Introduction}

Concealed multi-ribbed frame thermal insulation wall is a kind of environment-friendly wall, which is put forward under the background of energy saving and emission reduction, green recycling, low carbon and sustainable development ${ }^{[1]}$. The first step to build a wall by building blocks with special holes, then to pour reinforced concrete in these special holes, finally forms a complete wall. It is different from the ordinary reinforced concrete shear wall structure, but also different from the ordinary reinforced building block masonry shear wall structure ${ }^{[2-9]}$. Four models of Concealed multi-ribbed frame thermal insulation walls are manufactured at $1 / 2$ scale and then tested under eccentric load.

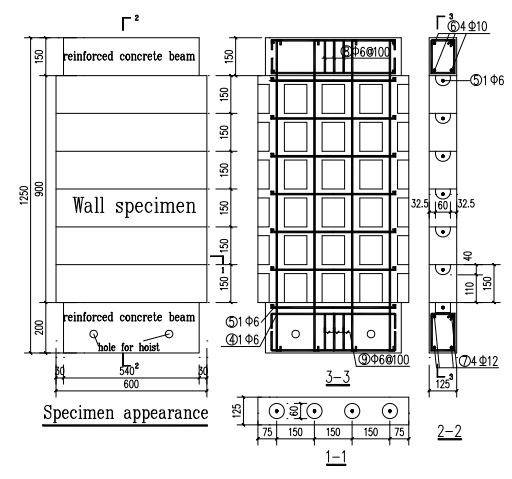

Figure 1. The size and reinforcement of the wall specimen

\section{Preparation}

\section{Test Specimen}

Four specimens which marked PW1 $\sim$ PW4 with the same height and the same reinforcement are designed, the common overall size is $600 \mathrm{~mm} \times 125 \mathrm{~mm} \times 900 \mathrm{~mm}$, ratio of height to thickness is 7.2 , the strength grade of concrete in the wall is C20. The eccentricity of load is $200 \mathrm{~mm}, 150 \mathrm{~mm}$, $100 \mathrm{~mm}, 50 \mathrm{~mm}$, In order to test the influence of different eccentricity on the bearing capacity and deformation of the wall. The reinforcement of the wall is shown in Figure 1. 


\section{Physical and Mechanical Properties of Materials}

Only one kind of reinforcement is arranged in the Concealed frame of the specimen, the test results of the mechanical properties of the reinforcement are shown in Table 1. The physical and mechanical properties of building blocks are listed in Table 2. The experimental and computational results of compressive strength of concrete in each specimen are shown in Table 3.

Table 1 Mechanical properties of reinforcement

\begin{tabular}{|l|l|l|l|l|l|l|}
\hline $\begin{array}{l}\text { Steel } \\
\text { grade }\end{array}$ & Nominal diameter(D) & $\begin{array}{l}\text { Measured cross-sectional area } \\
\left(\mathrm{mm}^{2}\right)\end{array}$ & $f_{y}\left(\mathrm{MP}_{\mathrm{a}}\right)$ & $f_{u}\left(\mathrm{MP}_{\mathrm{a}}\right)$ & $\begin{array}{l}\text { Elongation } \\
(\%)\end{array}$ & $\begin{array}{l}\text { Yield } \\
\text { strain } \\
(\%)\end{array}$ \\
\hline HPB300 & $\Phi 6$ & 32.37 & 541.31 & 553.02 & 12.31 & 0.258 \\
\hline
\end{tabular}

Table 2 Mechanical properties of building blocks

\begin{tabular}{|l|l|l|l|l|}
\hline $\begin{array}{c}\text { Dry bulk density } \\
\left(\mathrm{kg} / \mathrm{m}^{3}\right)\end{array}$ & $\begin{array}{l}\text { Rate of water } \\
\text { content }(\%)\end{array}$ & $\begin{array}{l}\text { Cubic compressive } \\
\text { strength }\left(\mathrm{N} / \mathrm{mm}^{2}\right)\end{array}$ & $\begin{array}{l}\text { prismatic compressive } \\
\text { strength }\left(\mathrm{N} / \mathrm{mm}^{2}\right)\end{array}$ & $\begin{array}{l}\text { Elastic modulus } \\
\left(\mathrm{N} / \mathrm{mm}^{2}\right)\end{array}$ \\
\hline 616 & 13.2 & 2.11 & 1.67 & 1105 \\
\hline
\end{tabular}

Table3 Experimental and Computational Results of Compressive Strength of Concrete

\begin{tabular}{|c|c|c|c|c|}
\hline Specimen & PW1 & PW2 & PW3 & PW4 \\
\hline Design strength & $\mathrm{C} 20$ & $\mathrm{C} 20$ & $\mathrm{C} 20$ & $\mathrm{C} 20$ \\
\hline Age (day) & 29 & 28 & 29 & 28 \\
\hline Average value of compressive strength $\left(\mathrm{MP}_{\mathrm{a}}\right)$ & 32.16 & 28.93 & 32.45 & 30.31 \\
\hline Characteristic value of cube strength $\quad\left(\mathrm{MP}_{\mathrm{a}}\right)$ & 29.68 & 28.72 & 30.99 & 29.96 \\
\hline Scaled value axial compressive strength $\quad\left(\mathrm{MP}_{\mathrm{a}}\right)$ & 21.51 & 19.35 & 21.71 & 20.27 \\
\hline
\end{tabular}

\section{Test and Analysis}

\section{Failure Process of Specimen}

PW1: When loading to $241.5 \mathrm{kN}$, there are some intermittent crackling sounds came from the wall. When loading to $339.1 \mathrm{kN}$, in the absence of warning, the central part of the specimen suddenly destroyed, Some block caving down and some concretes are crushed, also, reinforcement have already yielded. No cracks were found during the loading process.

PW2: When loading to $241.5 \mathrm{kN}$, there are some intermittent crackling sounds came from the wall. When loading to $322.1 \mathrm{kN}$, there are many dense vertical cracks in the compression area which at upper right of the wall, at the same time, horizontal cracks appear in the upper left side of the wall. When loading to $332.5 \mathrm{kN}$, the specimen was suddenly overwhelmed, part of block caving and some concretes are crushed, the steels are pulled off in the tensile zone and bent in the compression zone.

PW3: When loading to $155.0 \mathrm{kN}$, a horizontal crack appears on the top left of the wall, as the load increases, the crack extends into the interior and is getting wider, very soon there are other horizontal cracks. When loading to $160.0 \mathrm{kN}$, inside the wall came a "crackling" sound. When loading to $260.0 \mathrm{kN}$, there are many vertical cracks in the compression area which at right side of the wall. When loading to $298.3 \mathrm{kN}$, the wall is suddenly crushed. The failure of the wall is similar to PW2. 
Table 4 cracking and failure load

\begin{tabular}{|c|c|c|c|c|}
\hline Specimen & $\begin{array}{c}\mathrm{P} \\
\mathrm{W} 1\end{array}$ & $\begin{array}{c}P \\
\mathrm{~W} 2\end{array}$ & $\begin{array}{c}\mathrm{P} \\
\mathrm{W} 3\end{array}$ & $\begin{array}{c}P \\
\mathrm{~W} 4\end{array}$ \\
\hline $\begin{array}{l}\text { a: cracking } \\
\text { load }\end{array}$ & - & $\begin{array}{r}32 \\
2.1\end{array}$ & $\begin{array}{r}15 \\
5.0\end{array}$ & $0^{63 .}$ \\
\hline $\begin{array}{c}\text { b: } \\
\text { load }\end{array}$ & $\begin{array}{r}33 \\
9.1 \\
\end{array}$ & $\begin{array}{r}33 \\
2.5\end{array}$ & $\begin{array}{r}29 \\
8.3 \\
\end{array}$ & $\begin{array}{r}19 \\
1.2\end{array}$ \\
\hline$a / b(\%)$ & - & $\begin{array}{l}96 . \\
87\end{array}$ & $\begin{array}{c}51 . \\
96\end{array}$ & $\begin{array}{c}32 . \\
95\end{array}$ \\
\hline
\end{tabular}

PW4: When loading to $63.0 \mathrm{kN}$, some horizontal cracks appear on the top left of the wall, as the load increases, the cracks extend into the interior and more cracks are find at centre-left of the wall. When loading to $170.0 \mathrm{kN}$, some vertical cracks appear in upper right of the wall. as the load increases to $188 \mathrm{kN}$, the extension and width of the cracks are obvious. When loading to $191.2 \mathrm{kN}$, The wall is destroyed, the compression block and concrete are crushed, reinforcements are already yielded. The failure of the wall is ductile failure.

The cracking and failure load of each specimen are shown in table 4. the paper get some conclusions as follows: (1) The failure load is decreased according to the increase of eccentricity, which is consistent with the general stress characteristics of eccentric compression members. (2) The specimen of PW1、PW2 and PW3 showed a sudden and unexpected failure. Opposite, the failure Omen of PW4 is obvious. (3) The failure of each specimen is material failure. The buckling failure of out of plane is not happen.

\section{Cooperative Working Performance}

In the eccentric compression test, the Concealed frame and the block each bear a certain load, and influence each other, which will directly affect the mechanical performance and integrity of the wall. The stress-strain curve of vertical reinforcement and block in different eccentricity are shown in Figure 2. The picture shows: In the stage of elastic, the co deformation of wall materials is basically the same; In the stage of elastic-plastic, because of the appearance of cracks, the deformation consistency of block and concrete appears deviation, but the work synergy between materials is still good.

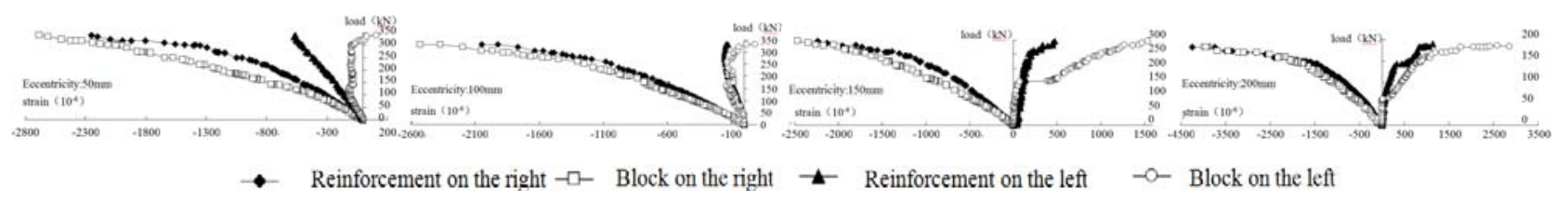

Figure 2 The stress-strain curve of vertical reinforcement and block in different eccentricity

\section{Failure Mode}

The failure modes of specimens with different eccentricity are different. At the time of loading, the specimens PW1, PW2 are basically full-section compressed; their destruction is a sudden brittle failure without warning. The failure of PW3 is similar to PW1, PW2, although the vertical reinforcements on left side of the wall is not yield in tension. The brittle failure of small eccentric compression occurred in specimens PW1, PW2 and PW3; it is characterized by compression zone 
of concrete and block crushing. When the specimen PW4 is damaged, the right concrete and the building block are crushed, and the left reinforcements are yield. This is an obvious omen of large eccentric compression failure.

\section{Analysis of Bearing Capacity}

\section{Equivalent Analysis of Material}

Due to the particularity of the structure and material composition of the Concealed frame insulation wall, according to the principle of equivalent strength, to calculate the section size and material of the wall is necessary. The strength of concrete and block is equivalent to the strength of concrete, do not change the position of reinforcements. Some assumptions are as follows: 1) The strain on the section of the wall conforms to the plane-section assumption. 2) Without considering the tensile strength of concrete and block. 3) The stress-strain curve of concrete is taken from literature [10]. 4) Only consider the elastic deformation of reinforcement. 5) The deformation between concrete and block is coordinated.

Take the effective width of the wall section $\mathrm{H}=510 \mathrm{~mm}$, then the effective equivalent-thickness after:

$$
B=\frac{E_{\mathrm{b}}\left(B_{1} H_{1}-\pi d^{2}\right)}{E_{\mathrm{c}} H}+6 \frac{\pi d^{2}}{H^{3}}\left(\frac{d^{2}}{8}+x_{1}^{2}+x_{2}^{2}\right)
$$

Where: H1-the original width of the wall; B1-the original thickness of the wall; $\mathrm{d}$-section-diameter of Concealed frame column; Ec,Eb- the elastic modulus of concrete and block; $\mathrm{x} 1, \mathrm{x} 2$ - the centroid distance from each Concealed frame column to the wall.

\section{Calculation Method and Result Comparison}

Through analysis, the wall can be equivalent to reinforced concrete shear wall, its bearing capacity can be calculated by the formula in [10]. The calculation results and the test results are shown in Table 5. It can be seen from the table, It is appropriate to calculate the bearing capacity of the Concealed multi-ribbed frame thermal insulation wall by the method.

Table 5 Theoretical calculation results and experimental results of bearing capacity

\begin{tabular}{|l|l|l|l|l|}
\hline Specimen & PW1 & PW2 & PW3 & PW4 \\
\hline Load condition & $\begin{array}{l}\text { Small } \\
\text { eccentricity }\end{array}$ & $\begin{array}{l}\text { Small } \\
\text { eccentricity }\end{array}$ & $\begin{array}{l}\text { Small } \\
\text { eccentricity }\end{array}$ & $\begin{array}{l}\text { big } \\
\text { eccentricity }\end{array}$ \\
\hline eccentricity $(\mathrm{mm})$ & 50 & 100 & 150 & 200 \\
\hline depth of compressive zone $x(\mathrm{~mm})$ & 408.0 & 388.8 & 335.2 & 252.0 \\
\hline a: Theoretical calculation results $(\mathrm{kN})$ & 317.2 & 271.3 & 252.5 & 167.9 \\
\hline b: experimental results $(\mathrm{kN})$ & 339.1 & 332.5 & 298.3 & 191.2 \\
\hline a/b & 0.94 & 0.82 & 0.85 & 0.88 \\
\hline
\end{tabular}

\section{Conclusions}

Through the above analysis, the calculation method of bearing capacity of the Concealed multi-ribbed frame thermal insulation wall under eccentric load is simple and high reliability. As a result, the theoretical calculation results of the ultimate bearing capacity matches well with the experimental results, which may provide a good reference for actual engineering calculation. 


\section{Acknowledgement}

Research Fund: Science Research Project of Zhejiang Provincial Department of Education (Y201225574).

\section{References}

[1] Information on http://www.gov.cn

[2] Heng-jun Sun, Guang-qiang Zhou, Experimental research on compressive behavior of reinforced masonry walls, J. Journal of Shandong Jianzhu University. 2006,21 (4) 316-320

[3] Hai-yan XU, Hai-hong XUE, Zhi-hua YUAN, Experimental and Theoretical Research on Load bearing Capacity of Z shaped R.C Columns,J. Journal of East China Jiaotong University, 2004,21 (1) 8-11

[4] Min-gang $\mathrm{Wu}$, Rui-yu Feng et al,The stability analysis of hollow shear wall with axial compression, J. Journal of Xi'an University Of Architecture And Technology, Natural Science Edition. 2002,34 (4) 358-361

[5] Sheng-cai Li, Experimental Investigation on composite wall panels under Axial Compression,J]. Journal of Huaqiao University, Natural Science Edition. 2006,27 (4) 384-387

[6] Ai-min Wang. Research on load-Bearing Performance and Design Method of Multi-ribbed Composite Wall in Moderate-high storied Multi-ribbed Slab Structure, D. Xi'an, Xi'an University Of Architecture And Technology, 2006

[7] Ren-zhuo Zang, Experimental Investigation on Behaviors of new Type Sandwich Panels, D. Beijing, Tsinghua University, 2004.

[8] Sheng-cai Li. Research on Compression-resisting behaviors of Energy-Saving Block \& Invisible Multi-Ribbed Frame structure Wall ( I ), Experimental part, R. Quanzhou, Huaqiao University, 2007

[9] Zhen-hai Guo, Xu-dong Shi, Reinforced concrete theory and analysis. Tsinghua University Press, Beijing, 2003

[10] GB50010-2010, Code for design of concrete structures, S. China Architecture \& Building Press, Beijing,2010 